\title{
Furúnculo Causado por CA-MRSA - Relato de Caso
}

Carlos Gustavo Carneiro de Castro', Camille Maximiliana de Toledo Leme Maia², Daniel Bialowas ${ }^{3}$, Fábio de Sá Guedes , Laila de Castro Peixoto Carvalho 5 , Livia Abreu Pereira Azis ${ }^{6}$, Glaura Tinoco Plata ${ }^{7}$

'Especialista em Dermatologia pela Sociedade Brasileira de Dermatologia (SBD)/Specialist in Dermatology by SBD, Brasil

${ }^{2}$ Clínica Médica/Medical Clinic, Hospital do Servidor Público Estadual de São Paulo, Brasil

${ }^{3}$ Acadêmico de Medicina do Sexto Ano/6th year Medical Student, Universidade Anhembi Morumbi, Brasil

${ }^{4}$ Graduado em Medicina/Graduated in Medicine, Fundação Técnico-Educacional Souza Marques (FTESM), Brasil

${ }^{5}$ Especialista em Atenção Básica em Saúde da família pela Universidade Federal de Mato Grosso (UFMS)/Specialist in Basic Atention

in Family Health, Brasil

${ }^{6}$ Graduada em Medicina pela Universidade Federal do Amazonas/Graduated in Medicine, Amazonas Federal University, Brasil

RESUMO - Nas últimas décadas, o desenvolvimento da resistência bacteriana aos diversos beta-lactâmicos relacionada a alterações codificadas pelo gene mecA, tem causado um aumento da incidência de infecção por Staphylococcus aureus meticilina-resistente adquirido na comunidade, antes apenas documentado em ambientes nosocomiais. Relatamos o caso de um paciente com furúnculos recorrentes que após realização de cultura e antibiograma evidenciou trata-se de infecção por community-associated meticillin-resistant Staphylococcus aureus (CA-MRSA). Na ocasião a terapêutica instituída foi baseada no antibiograma havendo regressão total do quadro.

PALAVRAS-CHAVE - Infecções Comunitárias Adquiridas; Furunculose; Staphylococcus aureus Resistente à Meticilina.

\section{Furuncle Caused by Community-Acquired Methicillin- Resistant Staphylococcus aureus - Case Report}

ABSTRACT - During the last decades methicillin-resistant Staphylococcus aureus (MRSA) infections occurring within communities - previously documented only in nosocomial environments - increased, in relation with the development of bacterial resistance to alterations coded by mecA gene. We present the case report of a patient with recurrent furunculosis, confirmed by culture and antibiogram to be a methicillin-resistant Staphylococcus aureus (MRSA) infection community-associated. Therapy, instituted according to antibiogram, lead to complete clinic resolution.

KEY-WORDS - Community-Acquired Infections; Furunculosis; Methicillin-Resistant Staphylococcus aureus.

\section{INTRODUÇÃO}

Furúnculo, em geral causada pelo Staphylococcus aureus (S. aureus), acomete o folículo piloso, a glândula sebácea e o tecido subcutâneo ao redor. ${ }^{5}$ Sua principal característica é a formação de um de um nódulo avermelhado, endurecido e quente, com uma área amarelada na parte central indicativa da presença de pus. ${ }^{5}$ Localiza-se principalmente em áreas de atrito, transpiração e na presença de folículos pilosos (como axilas e região glútea). ${ }^{2}$

O S. aureus encontra-se na pele e na cavidade nasal em cerca de $60 \%$ da população, mas sobretudo em pacientes com dermatite atópicos onde pode ser detectado em cerca de $100 \%$ dos casos em pele lesada. O S. aureus pode tornar-se patogênica em condições em que há quebra da barreira cutânea ou diminuição da imunidade, ${ }^{2,3}$ provocando impetigo, foliculites, furúnculos ou abcessos.

Ao longo do tempo esta bactéria passou por modificações adquirindo mecanismos de resistência a diversos antibióticos; hoje a variante $S$. aureus meticilina-resistente (MRSA), antes isolada especificamente em ambientes hospitalares, desde a década de 80 está sendo documentada de modo crescente como agente de infecções em pacientes da comunidade. Para estas cepas de estafilococos foi criada a denominação $S$. aureus meticilina-resistentes adquiridos na comunidade (CA-MRSA)..$^{3,6}$

Os primeiros relatos de CA-MRSA na América Latina foram
Correspondência: Dr. ${ }^{a}$ Camille Maximiliana de Toledo Leme Maia Rua Artur Prado, 389/ap.61, Bela Vista

CEP: 01322-000, São Paulo, Brasil - Tel.: +55 11 32534792/+55 11999848410

E-mail: cmtlm@hotmail.com
Recebido/Received

Outubro/October 2015

Aceite/Accepted

Dezembro/December 2015 


\section{Caso Clínico}

feitos no sul do Brasil, no início dos anos 2000 e desde então diversos casos foram relatados indicando um aumento na prevalência desta infecção em pacientes que não estiveram internados no ano antecedente ao da infecção, tampouco foram submetidos a diálise, cirurgias ou utilização de cateter.

O presente relato diz respeito a um paciente com furúnculos de repetição em que a cultura e o antibiograma revelaram infecção por CA-MRSA demonstrando a importância destes métodos laboratoriais para o diagnóstico e terapêutica.

\section{RELATO DE CASO}

Doente do sexo masculino, 37 anos, raça caucasiana, comerciante, natural e procedente do Rio de Janeiro procura - ambulatório de dermatologia com queixa de lesão eritematosa dolorosa na região lateral esquerda do tórax com aproximadamente 2 meses de evolução.

Relata também que ao longo desses 2 meses notou o surgimento de cerca de outras 8 lesões semelhantes a atual e em diferentes topografias como axilas, virilha e abdômen. $\mathrm{Na}$ ocasião elas foram tratadas sem investigação fazendo uso empírico de diversos antimicrobianos (cefalexina, cefadroxil e amoxicilina-clavulanato de potássio).

Informava ser hipertenso e diabético tipo 2, ambas as comorbidades em tratamento regular e satisfatório com anti-hipertensivos e hipoglicemiantes orais. Negava outras afecções cutâneas, assim como quadro semelhante na família ou em contactantes próximos. Negava também tabagismo, etilismo, uso de drogas, frequentar piscina ou outros ambientes comunitários, internações e cirurgias prévias.

Ao exame clínico dermatológico havia na face lateral esquerda do tórax nódulo único de aproximadamente $2,5 \times 2,0 \mathrm{~cm}^{2}$, doloroso a palpação, com consistência mole, sinais flogísticos, descamação perilesional e presença de pústula centrada sobre a lesão.

Diante do relato de recorrência e uso indiscriminado de antibióticos foi realizada a colheita do material e enviado para cultura e antibiograma que posteriormente evidenciaram infecção por $S$. aureus resistente à oxacilina/meticilina e sensível à clindamicina, sulfametoxazol-trimetopim (SMX-TMP), tetraciclinas e fluorquinolonas.

Baseado no perfil de sensibilidade do antibiograma o tratamento proposto foi o uso de sulfametoxazol/trimetoprim oral $(800 / 160 \mathrm{mg})$ de $12 \mathrm{em} 12$ horas durante 10 dias havendo regressão completa da lesão. O paciente fez uso também de mupirocina tópica na região nasal e sabonete líquido de gluconato de clorexidina $2 \%$ para descolonização.

Atualmente o paciente segue em acompanhamento ambulatorial, não apresentando recidivas do quadro até o momento.

\section{DISCUSSÃO}

No relato de caso em questão o paciente apresentava um quadro de furunculose recorrente e sem melhora com a terapia convencional, ainda que sem complicações sistémicas. Realizado a coleta do material, enviado para análise e que

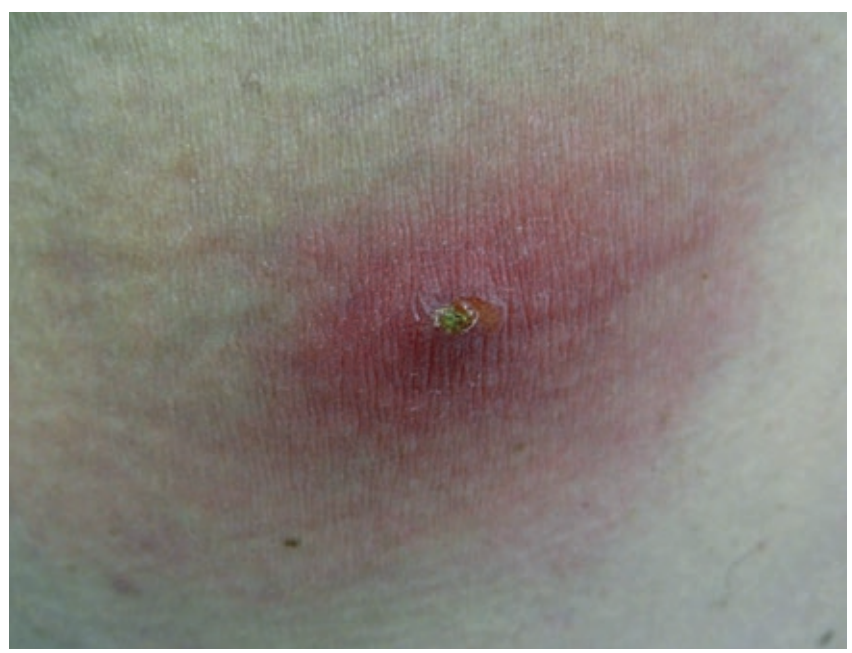

Figura 1 - Nódulo com 2,5x2,0cm, eritematoso, infiltrado, com pústula única central e localizado em hemitórax esquerdo.

demonstrou tratar-se de infecção por $S$. aureus meticilina-resistente, adquirido sem aparente exposição aos habituais fatores de risco hospitalar, portanto interpretado como CA-MRSA. ${ }^{6}$

O primeiro relato de uma forma de CA-MRSA ocorreu em 1993 na Austrália, detectado em populações indígenas locais. ${ }^{3} \mathrm{Na}$ América do Sul infecções causadas por este patógeno foram observadas em 2001 no Uruguai, e no Brasil os primeiros isolados foram na região Sul do país e tinham apresentação clínica de furunculose e artrite séptica. ${ }^{3}$ Estudos demonstraram que em 1990, 2,9\% dos S. aureus isolados eram meticilina-resistentes, no ano 2000 houve um aumento para $19 \%$ e em 2003 para $62,4 \%$ o que corrobora com o aumento progressivo da prevalência visto atualmente. ${ }^{7}$

O mecanismo de resistência à meticilina desenvolvido pela bactéria está relacionado com a produção de proteínas de ligação com a penicilina, as PBPs. ${ }^{8}$ As cepas MRSA expressam um novo tipo, a PBP2a que possui baixa afinidade a praticamente todos os antibióticos beta-lactâmicos. Esta proteína é codificada pelo gene mecA carreado por um elemento genético conhecido como cassete cromossômico estafilocócico (SCC). ${ }^{8}$

Existem cinco tipos de SCCmec: I, II, III, IV e V. Os três primeiros estão presentes nos MRSA hospitalares e os últimos são encontrados nos MRSA adquiridos na comunidade. ${ }^{8}$ Além disso o CA-MRSA possui a Panton-Valentine leucocidina uma toxina capaz de destruir os leucócitos humanos e causar necrose tecidual por meio da formação de poros na membrana celular. ${ }^{3,8}$

Embora a terapia ainda não esteja padronizada, os antimicrobianos orais que são geralmente ativos para as infecções por estes agentes incluem tetraciclinas, sulfametoxazol-trimetropim, fluorquinolones, minociclina e clindamicina. ${ }^{3}$ Para as formas clínicas graves, relacionam-se: vancomicina, linezolida, teicoplamina e tigeciclina. ${ }^{3}$

Como boa parte das infecções por CA-MRSA acometem 


\section{Caso Clínico}

tecidos como a pele e/ou partes moles, muitas vezes sem aspectos clínicos que a permitam distinguir facilmente das lesões causadas por outras estirpes de $S$. aureus sem resistência à meticilina a importância do médico dermatologista em relação ao domínio no manejo desta infecção é determinante. ${ }^{3} \mathrm{O}$ recurso habitual ao exame cultural e a utilização de antibióticos sob orientação do antibiograma deveriam ser a regra nestas circunstâncias.

Conflitos de interesse: Os autores declaram não possuir conflitos de interesse. Suporte financeiro: $O$ presente trabalho não foi suportado por nenhum subsídio ou bolsa. Confidencialidade dos Dados: Os autores declaram ter obtido consentimento escrito dos doentes para utilização dos seus dados clínicos e ter seguido os protocolos do seu centro de trabalho acerca da publicação dos dados de doentes.

Conflicts of interest: The authors have no conflicts of interest to declare. Financing Support: This work has not received any contribution, grant or scholarship. Privacy policy and informed consent: The authors declare that they have obtained informed consent from patients for the use of their medical data and followed the rules of the ethic committee of their center.

\section{REFERÊNCIAS}

1. Pereira AL, Leal F, Azulay DR, Azulay RD. Dermatologia. $6^{a}$ ed. Rio de Janeiro: Guanabara Koogan; 2013.

2. Tratamento das Principais Infecçoes Comunitárias e Relacionadas à assistência à Saúde e a Profilaxia antimicrobiana em Cirurgia. São Paulo: Anvisa; 2009.

3. Razera F, Stefani S, Bonamigo RR, Olm GS, Dias CAG, Narvaez GA. CA-MRSA em furunculose: relato de caso do sul do Brasil. An Bras Dermatol. 2009;84:515-8.

4. Santos AL. Staphylococcus aureus: visitando uma cepa de importância hospitalar. J Bras Patol Med Lab. 2007;43:413-23.

5. Alchome MM. Piodermites e outras dermatoses por bactérias. Livro Dermatologia Sampaio \& Rivitti. $3^{a}$ ed. São Paulo: Artes Médicas Editora; 2008.

6. Lopes HV. CA-MRSA: um novo problema para o infectologista. Rev Panam Infectol.2005; 7: 34-6.

7. Purcell K, Fergie J. Epidemic of Community-acquired methicilin-resistant Staphylococcus aureus infectious. Arch Pediatr Adolesc Med. 2005;159: 980-5.

8. Remonato G, Cardoso CM, Marques CG, Silva AE, Gelatti LC, Leite CF. CAMRSA:um patógeno emergente. News Lab 2007; 80:92-6. 